\title{
LII. On the delta radiation emitted by zinc when bombarded by alpha rays
}

\section{Professor J.C. McLennan F.R.S. \& C.G. Found M.A.}

To cite this article: Professor J.C. McLennan F.R.S. \& C.G. Found M.A. (1915) LII. On the delta radiation emitted by zinc when bombarded by alpha rays, Philosophical Magazine Series 6 , 30:178, 491-502, DOI: 10.1080/14786441008635424

To link to this article: http://dx.doi.org/10.1080/14786441008635424

Published online: 08 Apr 2009.

Submit your article to this journal $₫$

Џ Article views: 3

Q View related articles $\square$

Citing articles: 6 View citing articles 5 
In this connexion it is interesting to see that our results indicate that very probably the same equality would apply to the mobilities of positive and negative ions in liquid air. Measurements on the mobilities of ions in air at pressures still higher than those used in this investigation would be required, however, to show whether this surmise were correct or not.

In closing, we desire to express our appreciation of the services of $\mathrm{Mr}$. P. Blackman, who assisted us in taking many of the readings in this investigation.

The Physical Laboratory,

University of Toronto, May lst, 1915.

LII. On the Delta Radiation emitted by Zinc when bombarded by Alpha Rays. By Professor J. C. McLennan, F.R.S., and C. G. Found, M.A., University of Toronto *.

[Plate VII.]

\section{Introduction.}

TN some experiments by V. E. Pound $\dagger$ and described by I him in a paper: "On the Secondary Rays excited by Alpha Rays," he found that the delta radiation emitted by carbon when bombarded by the alpha rays from polonium increased very considerably when the temperature of the carbon was lowered from room temperature to the temperature of liquid air. He also showed that this increase in the delta radiation from carbon as its temperature was lowered was due to an increase in the amount of air occluded in the surface of the carbon.

Numerous observers have also found that the amount of a gas occluded in the surface of metals determines to a very considerable extent the intensity of the photo-electric effect exhibited by such metals when stimulated by ultra-violet light. Indeed, it was shown by Küstner $\ddagger$ that no photoelectric effect was exhibited by zinc even with wave-lengths as short as $\lambda=1850 \AA$. $U$. when the metal was scraped in a vacuum after extraordinary precautions had been taken to exclude gases, particularly the active ones. Wiedmann and

* Communicated by the Authors. Read before the Royal Society of Canada, May 26th, 1915.

+ Pound, Phil. Mag., November 1912.

† Küstner, Phys. Zeit. p. 68 (1914). 
Hallwachs * have shown, too, that the removal of occluded gases from potassium by repeated distillation in a very high vacuum caused its photo-electric effect to disappear completely with light which included wave-lengths down to $\lambda=3400 \AA$.U. The results of Küstner and Wiedmaun and Hallwachs have also been confirmed by Fredenhagen $\dagger$.

In addition, Hughes $\ddagger$ has shown that the contact difference of potential between zinc or bismuth, both distilled in vacuo, and platinum is exceedingly small when the surfaces of the zinc or bismuth consist of fresh deposit of the distilled metals. If traces of air, however, be admitted into the evacuated chamber containing the metals a great increase takes place in the contact difference of potential between the metals.

In view of all these experiments it was thought well to investigate what the effect would be on the intensity of the delta radiation from zinc under bombardment by alpha rays when care was taken to remove as far as possible all gases from the surface of the zinc bombarded. The following paper contains an account of this investigation, and from what follows it will be scen that with freshly prepared zine surfaces the delta-ray effect is exceedingly small, but that when air is permitted to be occluded in such surfaces a very great increase takes place in the magnitude of the effect.

\section{Apparatus.}

The apparatus used in conducting the experiments is similar to that used by Hughes $\S$ in his investigations on the photo-electric effect and is shown in fig. 1. It consisted of a glass tube about $3 \mathrm{~cm}$. in diameter and about $60 \mathrm{~cm}$. in length. This tube carried at its upper end a tap windlass $\mathrm{W}$ and at its lower end it was provided with a ground-joint for fitting it into the glass heating-chamber shown in the diagram. The tube was lined with a thin-walled brass tube which was kept joined to earth through a connexion at $E$. $B$ and $D$ were two guiding-rods of brass attached to the inner lining brass tube, and MN was a strip of brass which was supported by a cord from the windlass $W$ and had loops on its ends about the guiding-rods B and D. An insulated brass rod $\mathrm{H}$ was rigidly attached to $\mathrm{MN}$ through the intermediary of a short cylinder of amber A. It carried at its

* Wiedmann and Hallwachs, Verh. d. Deutsch. Phys. Ges. p. 107 (191t).

† Fredenhagen, Verh. d. Deutsch. Phys. Ges. p. 201 (1914).

t. Hughes, Phil. Mag., Sept. 1914, p. 337.

\$ Hughes, Phil. Trans. A. cexii. p. 205 (1912). 
lower end a small plate of zinc $X$ with a projecting piece $S$ which came into contact with the cup $\mathrm{C}$ when the rod $\mathrm{H}$ was raised by the windlass. A slender brass rod connected the cup $C$ to a sensitive electrometer. $P$ was a circular

Fig. 1.

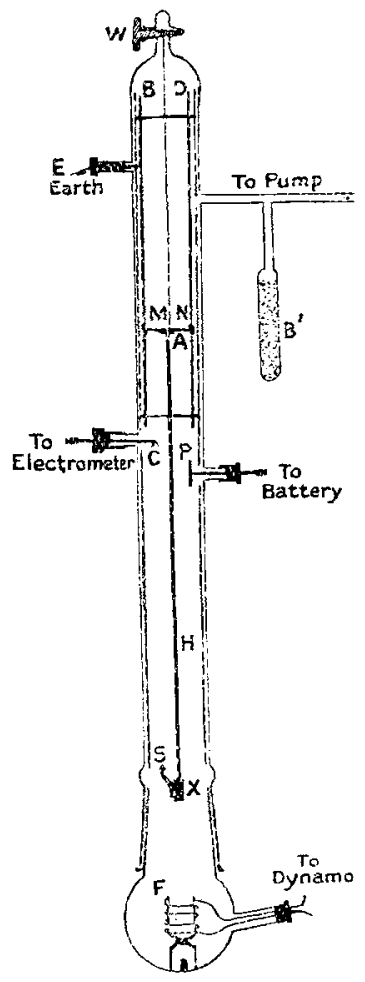

plate of copper $2 \mathrm{~cm}$. in diameter, with a deposit of polonium on its anterior face. As shown in the figure it could be connected as desired to either terminal of a battery of small storage-cells. The tube $\mathrm{B}^{\prime}$ was filled with coconut charcoal which was used for the purpose of improving the vacuum made with a Gaede rotary mercury-pump. F was a small fused quartz furnace-tube and was provided with platinum heating-coils as shown. It was held in an upright position by means of a short glass rod sealed into the base of the heating-chamber. When making zinc deposits on the surface of the zine plate $X$ the apparatus was first of all evacuated as highly as possible with the Gaede pump in 
conjunction with the coconut charcoal cooled with liquid air. Metallic zinc placed in $\mathrm{F}$ was brought to the boiling point with the heating coils, and the rod $\mathrm{H}$ was lowered so that the zinc plate $X$ was directly above the opening in $F$ and immersed in the issuing vapour. With this arrangement the zine plate could be readily coated with a fresh surfice when desired. In studying the delta radiation from this plate the rod $\mathrm{H}$ was raised with the windlass $\mathrm{W}$ until the projection $S$ was in electrical contact with the cup C. Under these conditions the zinc plate $\mathrm{X}$ was directly in front of the polonium-coated plate $\mathrm{P}$ and was subjected to bombardment by the alpha rays which were enitted by the latter.

It should also be mentioned that when in operation the tuke was set up with that portion about $P$ in the field and between the poles of an electromagnet.

\section{Experiments.}

Experiment I.-In commencing the investigation two experiments were carried out similar to those described by Logeman * in his paper on the emission of electrons from metals bombarded by alpha rays. In the first experiment a heating-jacket was placed about the tube containing the charcoal so as to drive the air out of the latter, and the apparatus was exhausted as highly as possible with a Gaede rotary mercury-pump. After this was done the heatingjacket was removed from $B^{\prime}$, and when the latter had dropped to room temperature it was surrounded with a Dewar flask and cooled with liquid air. When this was done a McLeod gauge attached to the apparatus showed that the pressure in the vessel had been reduced to considerably below '001 mm. of mercury. The zinc disk $X$, whose surface had been carefully scraped before it was inserted in the apparatus, was raised until contact was made between $S$ and $\mathrm{C}$. The polonium plate $\mathrm{P}$ was then charged to various positive potentials by means of the storage-battery, and the corresponding currents between $\mathrm{P}$ and $\mathrm{X}$ were measured with the Dolezalek quadrant electrometer joined to $\mathrm{C}$. The capacity of the quadrants and the attached electrical system was found to be 140 e.s.u.

The values of the applied potentials and the currents they produced are given in Table I., and a curve representing them is given in Pl. VII. fig. 2.

* Logeman, Proc. Roy. Soc., Series A, vol. Ixxviii. Sept. 6, 1907. 
TABLE I.

\begin{tabular}{|c|c|c|}
\hline \multicolumn{3}{|c|}{$\begin{array}{l}\text { Sensibility of Electrometer, } \mathrm{S},=220 \mathrm{~km} \text {. per volt. } \\
\text { Capaeity of Electrometer, } \mathrm{C},=140 \text { e.s.u. } \\
D=\text { deflexion in mm. Neale-divisions per minute. } \\
\text { The current, } i,=C . D . / 300.8 .60 \text { e.s.u. }\end{array}$} \\
\hline $\begin{array}{l}\text { Voltage on } \\
\text { Polonium. }\end{array}$ & $\begin{array}{l}\text { Deflexion in } \\
\text { mm. per min. }\end{array}$ & $\begin{array}{c}\text { Current } \times 10^{5} \\
\text { e.s.t. }\end{array}$ \\
\hline $\begin{array}{c}\text { Volts. } \\
0 \\
+2 \\
+4 \\
+6 \\
+10 \\
+16 \\
+22 \\
+28 \\
+40 \\
+50 \\
+60 \\
+80\end{array}$ & $\begin{array}{l}m m . \\
-35 \\
-23 \\
+3 \\
11 \\
16 \\
20 \\
20 \\
21 \cdot 5 \\
21 \\
23 \\
23 \\
23\end{array}$ & $\begin{array}{l}-127 \\
-80 \\
+11 \\
+40 \\
+58 \\
+73 \\
+73 \\
+78 \\
+76 \\
+84 \\
+84 \\
+84\end{array}$ \\
\hline
\end{tabular}

From the numbers in the Table and from the curve in fig. 2 it will be seen that, although the terminal $P$ was always either at zero or at a positive potential relative to $X$, the current was initially negative and remained so until a potential of about 4 volts was reached, when it passed through zero and became positive, gradually increasing to a maximum with an applied positive potential of about 40 volts.

In this experiment it will be noted that the current between $\mathrm{P}$ and $\mathrm{X}$ consisted of : (1) a very small positive current in the residual gas due to ionization ; (2) a positive current consisting of the stream of alpha particles emitted by the polonium; (3) a positive current consisting of a stream of recoil atoms from the polonium; (4) a positive current due to electrons passing from $X$ to $P$ arising from the bombardment of $X$ by the alpha particles; and $(5)$ a negative current due to electrons passing from $\mathrm{P}$ to $\mathrm{X}$ which accompanied the alpha particles and had their origin either in the polonium or in the copper surfaces on which the polonium was deposited. With zero or low positive voltages the stream of electrons mentioned in (5) it will be seen completely masked the other four constituents of the current. As the positive applied voltages, howover, were increased this stream of electrons was more and more prevented from leaving the electrode $\mathrm{P}$, and finally when a potential 
of 40 volts was reached, none escaped from $P$ at all, and the current became constant and consisted of the first four constituents mentioned above. This result was exactly in accordance with what Logeman had previously observed, and it showed that the apparatus was working satisfactorily.

Experiment II.-In the second experiment the poloniumcoated disk, $\mathrm{P}$, was kept joined to the positive terminal of the battery at a steady potential of 80 volts. This ensured that no electrons escaped from $\mathrm{P}$.

The electromagnet was then excited with currents of different intensities, and readings were taken on the corresponding currents through the chamber to the zinc plate $\mathrm{X}$. The results in one of the experiments of this type are given in Table II. and are represented graphically in PI. VII. fig. 3.

From these it will be seen that the current gradually fell off as the field was increased and ultimately reached a steady state with a field of approximately 1000 gauss.

'TABLE II.

\begin{tabular}{|c|c|c|c|}
\hline \multicolumn{4}{|c|}{ Voltage on polonium plate $=80$ volts, positive. } \\
\hline $\begin{array}{l}\text { Current, through } \\
\text { the coils of the } \\
\text { electromagnet. }\end{array}$ & $\begin{array}{l}\text { Value of the } \\
\text { magnetic field. }\end{array}$ & $\begin{array}{c}\text { Electrometer } \\
\text { deflexion per min. }\end{array}$ & $\begin{array}{c}\text { Current } \times 10^{5} \\
\text { e.s.u. }\end{array}$ \\
\hline $\begin{array}{c}\text { amps. } \\
\text { zero } \\
5 \\
1 \cdot 0 \\
1 \cdot 7 \\
2 \cdot 5 \\
3 \cdot 0 \\
3 \cdot 3 \\
3 \cdot 7 \\
4 \cdot 4 \\
4 \cdot 7 \\
5 \cdot 0 \\
6.0\end{array}$ & $\begin{array}{c}\text { gauss. } \\
\text { zero } \\
240 \\
410 \\
690 \\
905 \\
1020 \\
1100 \\
1190 \\
1275 \\
1300 \\
1330 \\
1400\end{array}$ & $\begin{array}{l}\text { nm. } \\
23 \cdot 0 \\
22 \cdot 3 \\
18 \cdot 0 \\
15 \cdot 0 \\
1 \cdot 0 \\
13 \cdot 2 \\
135 \\
11 \cdot 5 \\
1+0 \\
12 \cdot 7 \\
13 \cdot 7 \\
13 \cdot 7\end{array}$ & $\begin{array}{l}84 \\
72 \\
58 \cdot 3 \\
49 \\
45 \\
43 \\
44 \\
37 \\
45 \\
41 \\
44 \\
44\end{array}$ \\
\hline
\end{tabular}

From the known properties of the ionization currents of the alpha rays and of recoil atoms it is clear that a field of this intensity was not sufficient to modify to any appreciable extent the current carried by them to $X$, and it follows therefore that the decrease in the current observed was due to the action of the magnetic field in curling the electrons emitted by the zinc plate under bombardment by 
the alpha rays back agaiu into that plate. This experiment, therefore, showed that a field of 1000 gauss was sufficient when the applied potential difference was 80 volts to entirely cut off the stream of electrons. The problem before us, then, was to apply the procedure just described to the investigation of the intensity of the electronic stream from the zinc plate $\mathrm{X}$ when the surface of this plate was made to undergo various modifications.

Before leaving this experiment it may be pointed out that the results obtained go to show that approximately three electrons were emitted by the bombarded zinc plate for every alpha particle which struck it.

From the table it will be seen that the current under the electric field, combined with the maximum magnetic field, was approximately $44 \times 10^{-5}$ e.s.u. This current consisted of (1) alpha particles, (2) recoil atoms, and (3) the ionization current. As the gas-pressure in the apparatus was exceedingly low the ionization current must have been negligible. Taking it to be so the current must have been carried by the alpha particles and the recoil atoms. If, now, we assume that as many alpha particles were shot back into the polonium plate as were projected forward from it, it follows that the number of recoil atoms taking part in the current was very closely equal to the number of alpha particles which contributed to it. Taking the charge on the alpha particles to be $2 e$, and that on the recoil atom to be $e$, we have then, since the current carried by the electrons emitted by the zinc plate must have been $40 \times 10^{-5}$ e.s.u., the number of alpha particles striking $X$ given by $44 \times 10^{-5} / 3 e$. Since the number of electrons emitted by the zinc plate was $40 \times 10^{-5} / e$, it follows that 2.73 electrons were enitted by the zinc plate per alpha particle which struck it.

ExPeriment III.-The next experiment which was performed served to illustrate the fatigne of the delta-ray effect. In this case the apparatus was continuously evacuated for two days after the measurements made in experiments I. and II. were taken. At the end of this time readings were taken by applying various positive potentials up to 80 volts, and when this was reached the magnetic field was turned on and readings were taken with fields up to 1400 gauss. These are all recorded in Table III., and aro shown graphically in fig. 4 together with the results of experiments I. and II. From the results it will be seen that while the maximum current under 80 volts was $84 \times 10^{-5}$ e.s.u. at the beginuing of the experiment, it was only $63 \times 10^{-5}$ e.s.u. after two Plil. Mag. S. 6. Vol. 30. No. 178. Oct. 1915. $2 \mathrm{~K}$ 
days' evacuation. With an applied potential difference of 80 volts and a magnetic field of 1400 gauss, however, the readings obtained on the two occasions were practically the same. This showed that the current carried by the alpha particles and the recoil atoms remained the same for the two days, but that in the interval the electronic current from the zinc plate under bombardment by the alpha rays had dropped from $40 \times 10^{-5}$ e.s.u. to $18 \times 10^{-5}$ e.s.u.

TABLE III.

\begin{tabular}{|c|c|c|c|c|}
\hline $\begin{array}{l}\text { Voltage on } \\
\text { Polonium. }\end{array}$ & $\begin{array}{c}\text { Current } \\
\text { through coils. }\end{array}$ & $\begin{array}{l}\text { Magnetic } \\
\text { field. }\end{array}$ & $\begin{array}{l}\text { Deflexion } \\
\text { per min. }\end{array}$ & $\begin{array}{c}\text { Current } \times 10^{5} \\
\text { e.s.u. }\end{array}$ \\
\hline $\begin{array}{c}\text { Volts. } \\
\text { zero } \\
2 \\
4 \\
8 \\
14 \\
20 \\
40 \\
60 \\
80 \\
80 \\
80 \\
80 \\
80 \\
80 \\
80 \\
80 \\
80\end{array}$ & $\begin{array}{c}\text { amps. } \\
\text { zero } \\
\text { " } \\
" \\
" \\
" \\
" \\
, \\
" \\
.8 \\
1 \cdot 0 \\
1.7 \\
2 \cdot 5 \\
3.5 \\
4 \cdot 4 \\
5 \cdot 0 \\
5 \cdot 7\end{array}$ & $\begin{array}{c}\text { gauss. } \\
\text { zero } \\
:, \\
", \\
, " \\
", \\
, " \\
", \\
240 \\
410 \\
690 \\
905 \\
1140 \\
1275 \\
1330 \\
1390\end{array}$ & $\begin{array}{c}11 m . \\
-10 \\
-6 \\
11 \\
19 \\
21 \\
21 \\
21 \cdot 7 \\
20 \cdot 5 \\
21 \cdot 2 \\
19 \cdot 5 \\
17 \cdot 8 \\
16 \cdot 5 \\
14 \cdot 8 \\
14 \cdot 5 \\
15 \\
15 \\
15\end{array}$ & $\begin{array}{c}-29 \cdot 5 \\
-17 \cdot 0 \\
30 \\
56 \\
62 \\
62 \\
64 \\
60 \\
62 \cdot 6 \\
57 \cdot 6 \\
53 \\
49 \\
44 \\
43 \\
44 \\
44 \\
44\end{array}$ \\
\hline
\end{tabular}

This result made it evident that the electronic stream from the zinc plate was determined to a considerable extent by the amount of air occluded in its surface. For it is clear that under the continuous evacuation for two days there must have been a gradual diniinution in the amount of air occluded in the metal, and as everything else in the experiment remained the same this diminution must have been the cause of the decrease in the stream of delta radiation.

ExperimenT IV.-In this experiment a freshly cleaned plate of zinc was attached to the $\operatorname{rod} H$ at $X$, and the apparatus was left full of air at atmospheric pressure for six days. It was then exhausted as highly as possible with the Gaede pump and the coconut charcoal surrounded with liquid air.

Readings were first taken with positive potentials applied to $\mathrm{P}$ up to 80 volts, and then keeping the potential of $\mathrm{P}$ at 
emitted by Zinc lombarded by Alpha Rays.

80 volts positive readings were taken with increasing magnetic fields up to 1245 gauss. These readings are given in Table IV., and the curve representing them is shown in Pl. VII. fig. 5.

TABLE IV.

\begin{tabular}{|c|c|c|c|c|}
\hline \multicolumn{5}{|c|}{$\begin{array}{l}\text { Zine surface first scraped clean and then exposed to air } \\
\text { at atmospheric pressure for six days. }\end{array}$} \\
\hline $\begin{array}{l}\text { Voltage on } \\
\text { Polonium. }\end{array}$ & $\begin{array}{c}\text { Current } \\
\text { through } \\
\text { coils. }\end{array}$ & $\begin{array}{l}\text { Magnetic } \\
\text { field. } \\
\text { Gauss. }\end{array}$ & $\begin{array}{l}\text { Deflexion } \\
\text { per min. }\end{array}$ & $\begin{array}{c}\text { Current } \\
\times 10^{5} \\
\text { e.s.u. }\end{array}$ \\
\hline $\begin{array}{c}\text { Volls. } \\
\text { zero } \\
+2 \\
6 \\
60 \\
10 \\
14 \\
20 \\
26 \\
30 \\
40 \\
60 \\
80 \\
80 \\
80 \\
80 \\
80 \\
80 \\
80 \\
80 \\
80 \\
80 \\
80\end{array}$ & $\begin{array}{c}\text { amps. } \\
\text { zero } \\
\text { ", } \\
", \\
", \\
" \\
" \\
" \\
" \\
, \\
, \\
\cdot 5 \\
.95 \\
1 \cdot 3 \\
1 \cdot 65 \\
2 \cdot 3 \\
2 \cdot 8 \\
3 \cdot 3 \\
3 \cdot 6 \\
3 \cdot 9 \\
4 \cdot 2\end{array}$ & $\begin{array}{c}\text { zero } \\
" " \\
" \\
", \\
", \\
", \\
", \\
", \\
", \\
240 \\
405 \\
570 \\
1800 \\
860 \\
995 \\
1100 \\
1160 \\
1205 \\
12+5\end{array}$ & $\begin{array}{l}\text { mm. } \\
-8 \\
5 \\
22 \\
24 \cdot 5 \\
25 \\
26 \\
26 \\
26 \\
26 \\
26 \\
26 \\
23 \\
23 \\
22 \cdot 5 \\
20 \\
17 \\
15 \\
14 \cdot 5 \\
14 \\
14 \\
14\end{array}$ & $\begin{array}{c}-25 \\
16 \\
69 \\
77 \\
79 \\
82 \\
82 \\
8.3 \\
82 \\
82 \\
82 \\
72 \\
73 \\
71 \\
63 \\
53 \\
47 \\
456 \\
44 \\
44 \\
44\end{array}$ \\
\hline
\end{tabular}

From these it will be seen that the maximum current obtained without any magnetic field was $82 \times 10^{-5}$ e.s.u., but that with the magnetic field applied the current fell to $44 \times 10^{-5}$ e.s.u., and this current, as was pointed out before, consisted of (1) the residual ionization current, (2) the stream of alpha particles from $P$, and (3) the stream of recoil atoms from the same source.

After this set of readings had been taken the liquid air was taken from about the charcoal which was then allowed to rise to room temperature. The heating-jacket was then placed round it and its temperature gently raised so as to drive off as much of the occluded air as possible. While this was being done the Gaede pump was kept constantly in action. Meanwhile the rod $\mathrm{H}$ was lowered with the windlass $W$ until the plate $X$ was directly over the furnace $F$ 
and about $2 \mathrm{~cm}$. above it. When the pressure had been reduced to below $001 \mathrm{~mm}$. of mercury a current of 10 amperes was passed through the platinum wire of the furnace for 15 minutes. This sufficed to vapourize the zine in the furnace and to deposit a good coating on the surface of the zinc plate $X$.

The furnace current was then cut off and the rod $\mathrm{H}$ was raised as quickly as possible until contact was made with $\mathrm{S}$ at C. A positive potential of 80 volts was then applied to $P$, and readings were taken with increasing magnetic fields at intervals of a few minutes for half an hour.

The magnetic field was then cut off, and at the end of 55 minutes readings were again taken at intervals for half an hour with electric fields ranging from zero to 80 volts. At the end of 90 minutes a reading was taken with an applied field of 80 volts and a magnetic field of 1200 gauss, and at the end of 190 minutes a reading was again taken under the same conditions.

All these readings are recorded in Tables V. and VI., and curves drawn from them are shown in Pl. VII. figs. 6 and 7.

Table V.

\begin{tabular}{|c|c|c|c|c|c|}
\hline \multicolumn{6}{|c|}{ Zine surface deposited from zine rapour in a high vacuum. } \\
\hline $\begin{array}{l}\text { Voltage on } \\
\text { l'olonium. }\end{array}$ & $\begin{array}{l}\text { Current } \\
\text { through } \\
\text { coils. }\end{array}$ & $\begin{array}{l}\text { Mugnetic } \\
\text { field. } \\
\text { Crauss. }\end{array}$ & $\begin{array}{c}\text { Time since } \\
\text { surface } \\
\text { made. }\end{array}$ & $\begin{array}{l}\text { Deflexion } \\
\text { per } \\
\text { minute. }\end{array}$ & $\begin{array}{l}\text { Current } \\
\times 10^{5} \\
\text { e.s.u. }\end{array}$ \\
\hline $\begin{array}{c}\text { Volts. } \\
+80 \\
80 \\
80 \\
80 \\
80 \\
80 \\
80 \\
\text { zero } \\
2 \\
6 \\
10 \\
14 \\
20 \\
26 \\
30 \\
40 \\
60 \\
80\end{array}$ & $\begin{array}{c}\text { amps. } \\
\text { zero } \\
\cdot 5 \\
95 \\
1 \cdot 65 \\
2 \cdot 3 \\
2 \cdot 8 \\
36 \\
\text { zero } \\
", \\
" \\
" \\
" \\
" \\
" \\
" \\
" \\
" \\
"\end{array}$ & 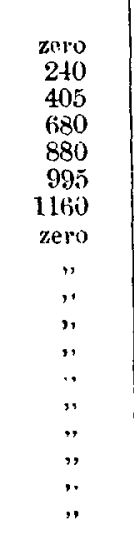 & $\begin{array}{c}\min . \\
5 \\
11 \\
15 \\
18 \\
23 \\
28 \\
30 \\
55 \\
58 \\
60 \\
62 \\
65 \\
67 \\
70 \\
72 \\
75 \\
77 \\
85\end{array}$ & $\begin{array}{r}\mathrm{mm} . \\
53 \\
52 \\
53 \\
52 \\
53 \\
53 \\
53 \\
-21 \\
0 \\
19 \\
23 \\
22 \\
25 \\
25 \\
25 \\
25 \\
25 \\
25\end{array}$ & $\begin{array}{r}166 \\
163 \\
166 \\
163 \\
166 \\
166 \\
166 \\
-\quad 66 \\
0 \\
60 \\
72 \\
69 \\
78 \\
78 \\
78 \\
78 \\
78 \\
78\end{array}$ \\
\hline
\end{tabular}


TABLE VI.

\begin{tabular}{|c|c|c|c|c|c|c|}
\hline \multicolumn{7}{|c|}{ Zine surface deposited from zine vapour in a ligh vacuum. } \\
\hline \multirow{2}{*}{$\begin{array}{l}\text { Time since } \\
\text { surface } \\
\text { was made. }\end{array}$} & \multicolumn{3}{|c|}{ Electric field alone. } & \multicolumn{3}{|c|}{ Electric and mugnetic field. } \\
\hline & $\begin{array}{c}\text { Deflexion } \\
\text { per } \\
\text { minute. }\end{array}$ & & & $\begin{array}{c}\text { Deflexion } \\
\text { per } \\
\text { minute. }\end{array}$ & & \\
\hline$\underset{10}{\min }$ & ${ }_{53}^{m}$ & $106 \times$ & e.s.u. & $\min _{53}$ & $166>$ & e.s.u. \\
\hline 30 & 43 & 135 & ," & 43 & 135 & $"$ \\
\hline 90 & 25 & 79 &. & 22 & 69 & $"$ \\
\hline 190 & 19 & 60 & , & 15 & 47 & , \\
\hline
\end{tabular}

One point which is brought out very prominently by these readings is that for the first half hour the current between $P$ and $X$, under a potential difference of 80 volts was the same whether a magnetic field, as high even as 1160 gauss, was applier or not. From this it was manifest that during this interval there was practically no emission of electrons from the newly deposited zinc surface, under bombardment by the alpha rays. It will be noted, too, that during the interval the saturation current was about $165 \times 10^{-5}$ e.s.u., which was about twice as great as that saturation current obtained in the previous experiment with the ordinary zinc plate without the fresh deposit. This was very probably due to the air-pressure in the apparatus being somewhat higher immediately after the deposit had been than it was when the observations were made with the zinc plate in its original condition. Even with the Gaede pump in action the effect of heating the furnace would be to drive off a considerable quantity of air from the walls of the vessel into the apparatus, and as the volume of the apparatus was considerable it would take time to remove this air again. That this interpretation was the correct one is shown by the readings taken in the second period extending from 55 minutes after the deposit had been made up to 85 minutes after that time. These, it will be seen, show that with increasing positive potentials the current increased and finally reached a maximum of only $78 \times 10^{-5}$ electrostatic unit. This would indicate that during the first half hour the ionization constituent of the current was very considerable, as it should have been on account of the higher air-pressure, while at the ond of 
85 minutes after the deposit had been made it was much less, on account of the removal of the air from the apparatus.

The numbers given in Table VI. and the curves in fig. 7 are also of interest in this connexion, for they show not only that the current gradually diminished with the lapse of time owing to the diminution of the ionization current constituent arising from the gradual reduction of the air-pressure, but also that there was a gradual increase in the electronic stream from the zine plate with the lapse of time under the bombardment by the alpha rays.

From what has gone before it is evident that this development of a delta radiation from the zinc plate arose from the gradual ocelusion of air into the surface of the zinc.

For, as the vapour was deposited on the zine plate in a high vacuum the surface would not contain any air first. It would not, however, in this state be in an equilibrium condition, and a tendency towards absorption would exist. The result of this would be that so long as air was present in the apparatus, absorption would take place at least until an equilibrium was established between the air occluded in the surface and that within the apparatus. This gradual occlusion of the air by the zine surface would therefore appear to account for, and to be the cause of, the gradual development of the electronic current.

\section{Summary of Results.}

I. In the present investigation it has been shown that when a plate of zine with a freshly scraped surface is placed in a bighly exhausted chamber and bombarded by alpha rays, there is an emission of slow-moving electrons or delta rays from it at the rate of three electrons for each alpha particle impact.

II. It has also boen shown that the emission of electrons from such a plate of zinc under bombardment by alpba rays diminished with the lapse of time from the moment when it was placed in the high vacuum.

III. It has also been shown that initially there is no emission of electrons under bombardment by alpha rays from a surface of zine deposited from zinc vapour in a high vacuum, but that as time elapses an electronic emission is gradually developed under the gradual absorption of air by the surfice of the rinc deposit.

'The Physicul I aboratory,

University of 'Toronto.

May lst, 1915. 
FIG. 2.

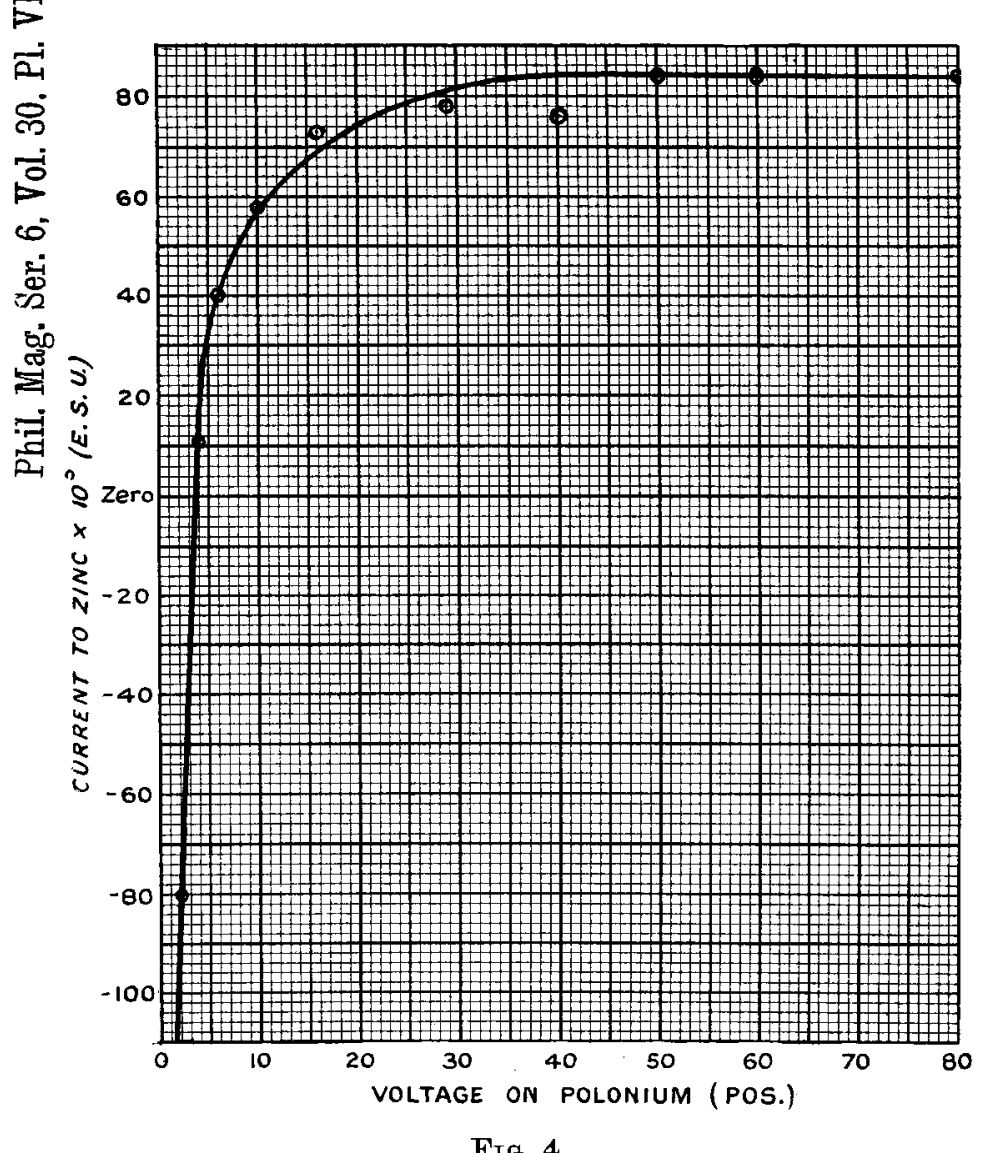

FIG. 4.

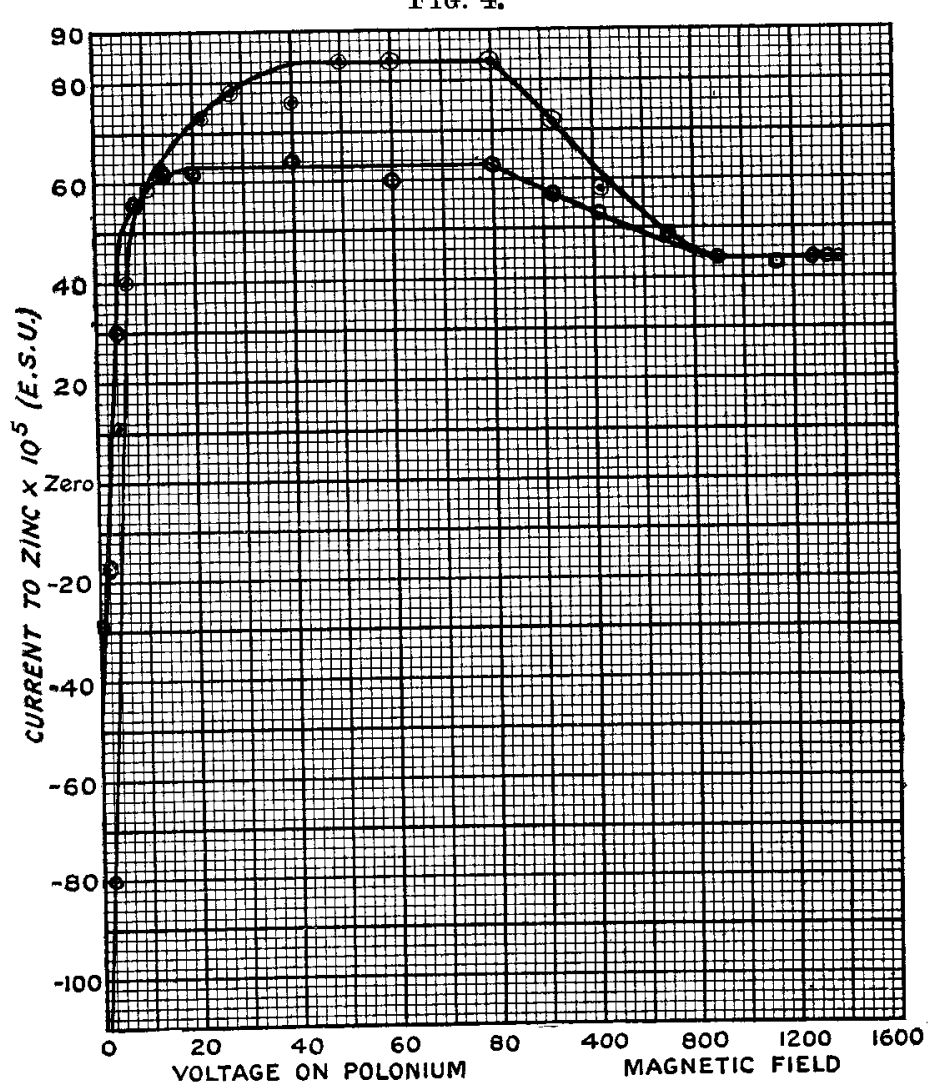

Fia. 6.

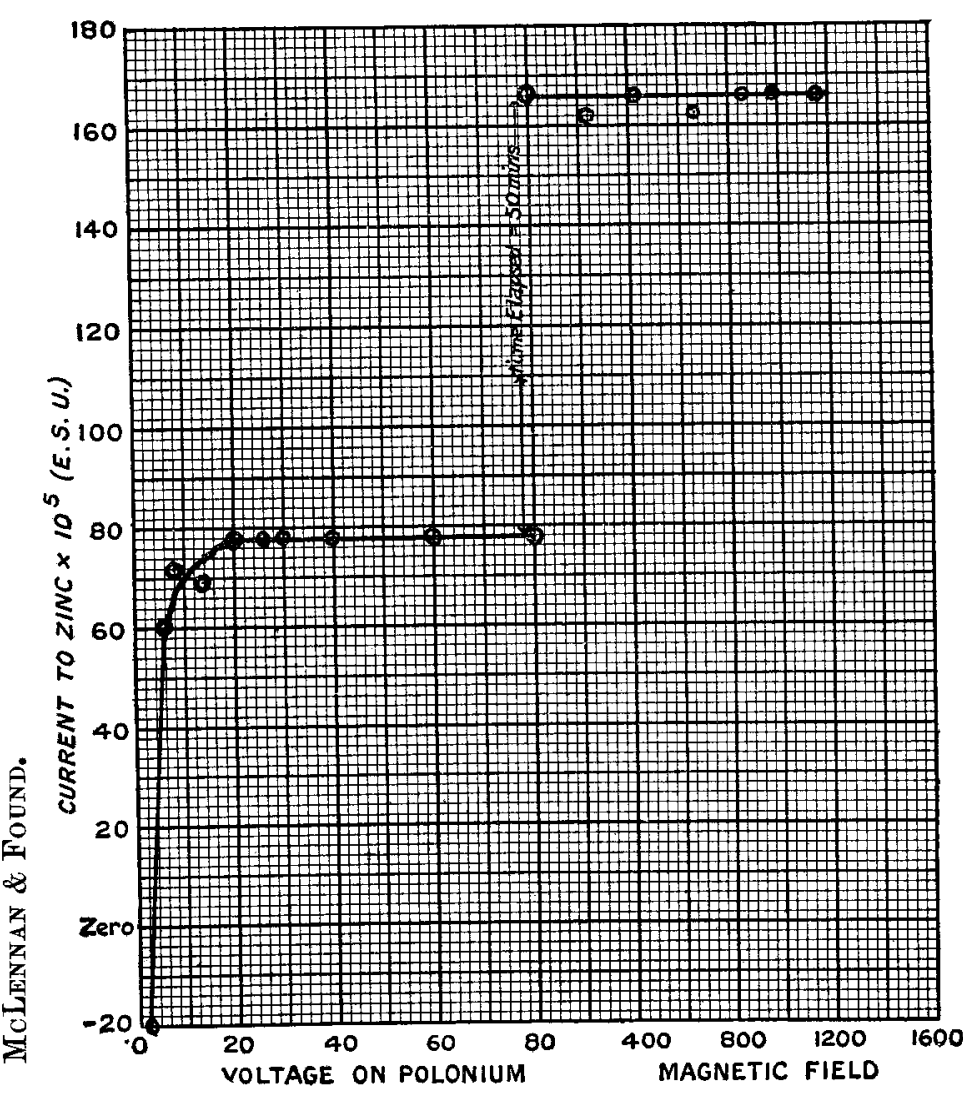

FIG. 3.
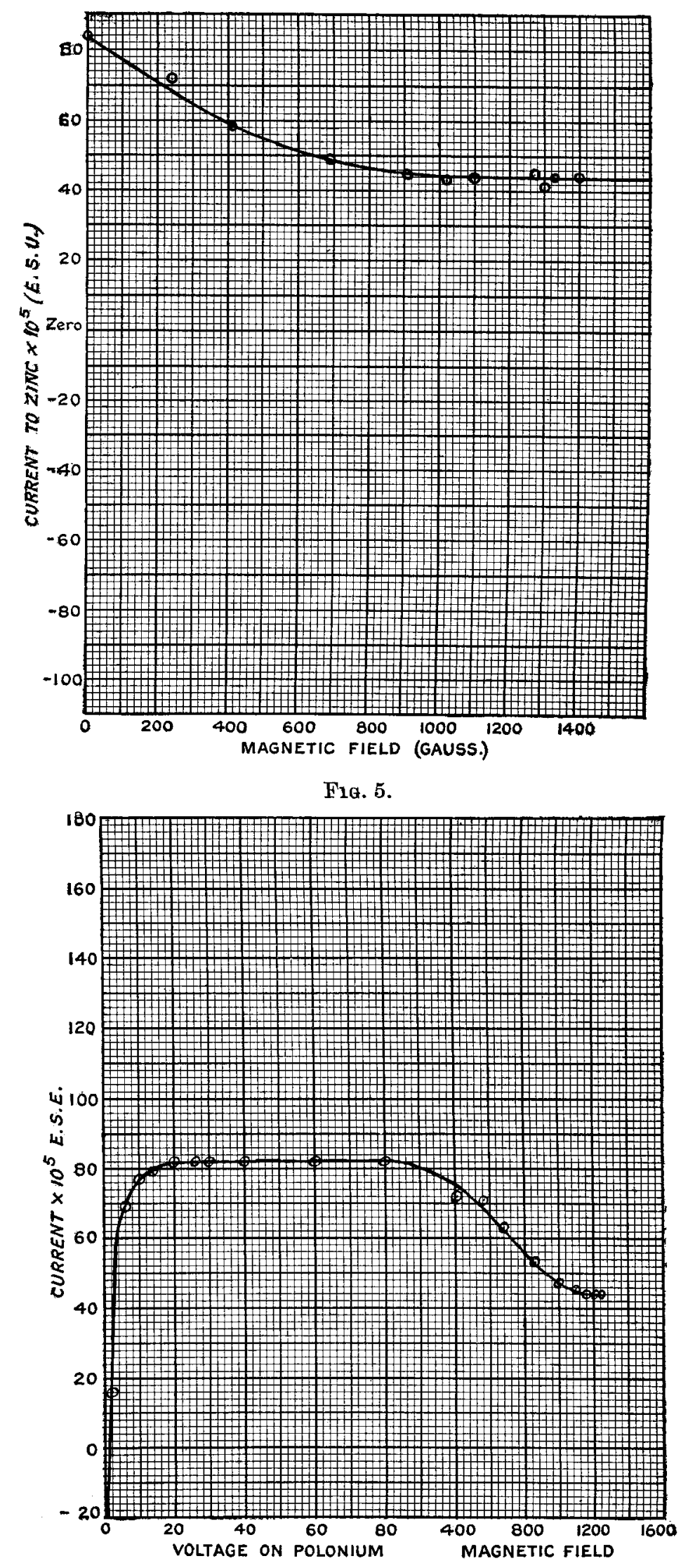

FIG. 7.

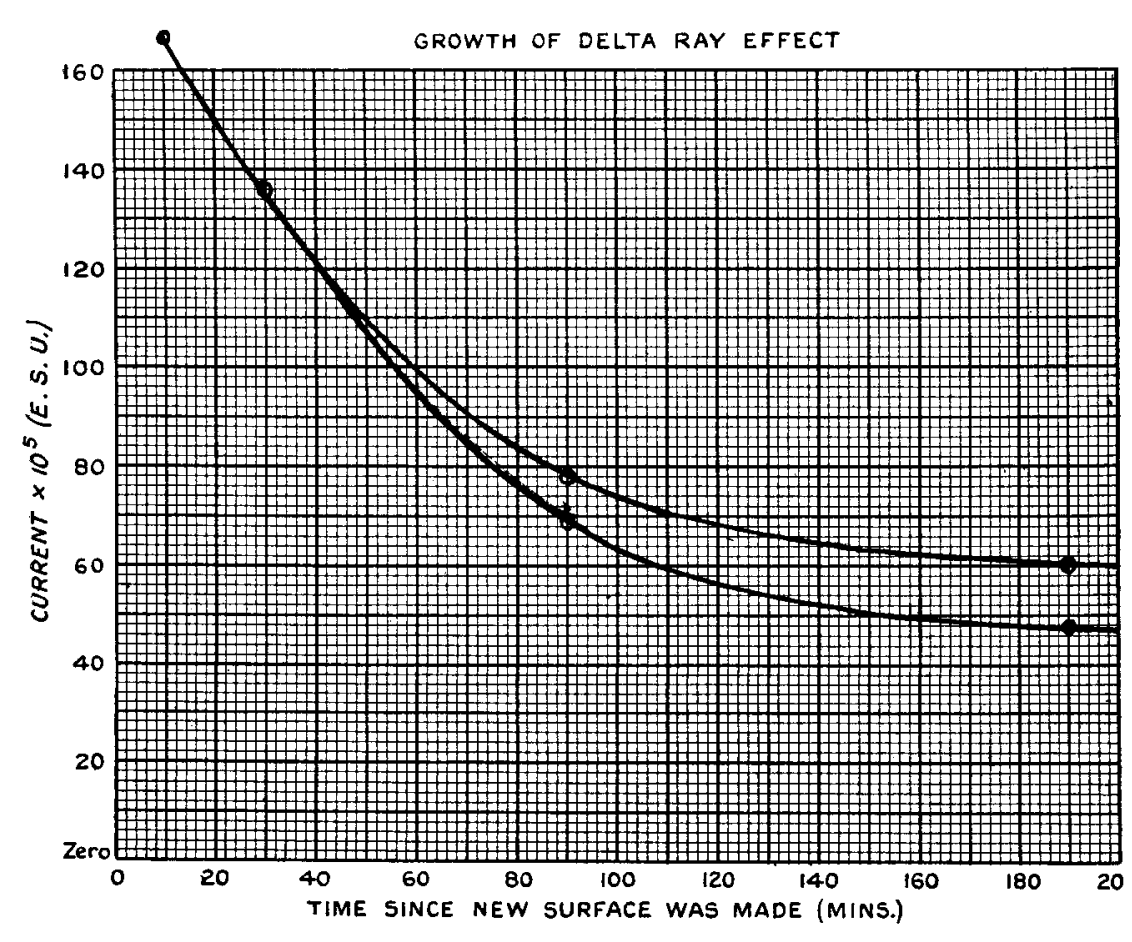

